\title{
PDX1 homeobox protein expression in pseudopyloric glands and gastric carcinomas
}

\author{
H Sakai, Y Eishi, X-L Li, Y Akiyama, S Miyake, T Takizawa, N Konishi, M Tatematsu, M Koike, \\ Y Yuasa
}

See end of article for authors' affiliations

Correspondence to: Professor Y Yuasa, Department of Molecular Oncology, Graduate School of Medicine and Dentistry, Tokyo Medical and Dental University, 1-545, Yushima, Bunkyo-ku, Tokyo 113-8519, Japan; yuasa.monc@tmd.ac.jp

Accepted for publication 30 September 2003

\begin{abstract}
Background and aims: Although it has been reported that intestinal metaplasia implicated in gastric carcinogenesis is induced by the ParaHox gene CDX2, it is unclear which genes are responsible for the formation of pseudopyloric glands and whether they play a role in gastric carcinogenesis. Pancreaticduodenal homeobox 1 (PDXI) is also a ParaHox gene which contributes to the genesis and development of the pancreas, duodenum, and antrum. To clarify its significance for the formation of pseudopyloric glands and gastric carcinogenesis, we investigated expression of PDX1 and mucin in gastric carcinomas and surrounding mucosa.

Methods: Gastric carcinoma tissues from 95 patients were used for immunohistochemical analyses of PDX1, and mucins MUC6 and MUC5AC.

Results: PDXI was found to be frequently expressed in pseudopyloric glands and intestinal metaplasia. MUC6 was more abundant than MUC5AC in pseudopyloric glands while higher levels of MUC5AC than MUC6 were evident in intestinal metaplasia. The frequency of PDXI positive reactivity was higher in differentiated type carcinomas $(39 / 43,90.7 \%)$ and $\mathrm{T1}$ carcinomas $(42 / 43,97.7 \%)$ than in undifferentiated type $(33 / 52,63.5 \%)$ and T2-4 $(30 / 52,57.7 \%)$ carcinomas. PDXI and MUC6 double positive expression was observed in carcinomas, respectively, including the corpus, and also correlated with histological type and depth of invasion. In contrast, no link was apparent between PDXI and MUC5AC double positive reactivity and histological type.

Conclusion: Our study suggests that PDX1 plays an important role in the development of pseudopyloric glands, and that pseudopyloric glands may reflect a condition associated with gastric carcinogenesis.
\end{abstract}

G astric carcinomas are histologically classified into intestinal and diffuse types by the Laurén classification. ${ }^{1}$ Corresponding terms for these carcinomas are low (well and moderately differentiated types) and high (poorly differentiated type) grade according to the WHO histological classification, ${ }^{2}$ and differentiated and undifferentiated types in the classification proposed by the Japanese Gastric Cancer Association ${ }^{3}$ according to the gland forming tendency. Patients with resected early gastric carcinoma have a good prognosis, their five year survival rate being approximately $95 \% .^{2}{ }^{4}$ Differentiated type gastric carcinomas are found in about $60 \%$ of early gastric carcinomas ${ }^{4}$ and approximately $80 \%$ of minute carcinomas less than $5 \mathrm{~mm} .^{56}$ In contrast, cases with undifferentiated tumours often have a worse prognosis. ${ }^{2}$ Differentiated type gastric carcinomas are thought to arise from intestinal metaplasia, ${ }^{7}$ which in turn is found in cases of atrophic gastritis. ${ }^{7}$ Pseudopyloric glands are also often seen in the mucosa affected by atrophic gastritis ${ }^{8}$ and are regenerative in nature as wound healing of the gastric mucosa. ${ }^{90}$ Cells with clear cytoplasm comprise pseudopyloric glands as well as pyloric glands, replacing glands of the corpus during regeneration. ${ }^{9}{ }^{10}$

Recently, it has been proposed that several homeobox proteins may be positive or negative tumour modulators. ${ }^{11}$ We have reported that the caudal homeobox gene CDX2 is significantly expressed in intestinal metaplasia and differentiated type gastric carcinomas. ${ }^{12}$ CDX2 is a member of the ParaHox family ${ }^{13}$ and functions as a transcription factor during the development of the intestine, but is normally absent from the stomach and oesophagus. ${ }^{14}$ Recently, forced expression of $\mathrm{Cdx} 2$ in the gastric mucosa of transgenic mice demonstrated that $\mathrm{Cdx} 2$ alone is sufficient to cause intestinal metaplasia in the stomach. ${ }^{15}$ However, it is unclear which genes are responsible for the formation of pseudopyloric glands and whether other homeobox genes are associated with gastric carcinogenesis.

Pancreatic-duodenal homeobox 1 (PDXl), also known as IPF-1, STF 1, or IDX-1, is another transcription factor in the ParaHox gene family ${ }^{13}{ }^{16}$ which plays an essential role in the genesis and development of the pancreas, duodenum, and antrum. ${ }^{17}{ }^{18}$ In adults, PDXI expression is observed in the nuclei of pancreatic $\beta$ cells, Brunner's glands of the duodenum, and pyloric glands of the stomach. ${ }^{18}{ }^{19} P d x I$ knockout mice exhibit pancreatic agenesis and abnormal formation of the pylorus and duodenum. ${ }^{17} 20$ The human $P D X 1$ gene is located at chromosome $13 q 12.1$ in the vicinity of the CDX2 gene. ${ }^{13}$ Given the important role of the latter in the formation of intestinal metaplasia, ${ }^{12}{ }^{1521}$ it is of interest to examine whether PDXl might have an equivalent link to pseudopyloric glands.

To clarify the role of PDXI in the formation of pseudopyloric glands and gastric carcinogenesis, we investigated PDX1 expression in gastric carcinomas and surrounding mucosa. We show that PDXI is indeed activated at various states of gastric carcinogenesis, providing a novel diagnostic marker, and suggesting that PDX1, like CDX2, contributes to the

Abbreviations: PDX1, pancreatic-duodenal homeobox 1; MUC6, MUC5AC, mucins MUC6 and MUC5AC; PCR, polymerase chain reaction; GST, glutathione-S-transferase; GST-PDX1, glutathione-Stransferase-PDX1 fusion protein; PBS, phosphate buffered saline; PBST, PBS and $0.05 \%$ Tween 20 
aberrant differentiation that accompanies carcinogenesis in the stomach.

\section{MATERIALS AND METHODS Tissue samples and histological examination}

In this study, we analysed 95 cases of primary gastric carcinomas, classified as categories $4.2,4.3,4.4$, and 5 by the Vienna classification, ${ }^{22} 23$ which were resected in the Affiliated Hospital of the School of Medicine, Tokyo Medical and Dental University, between 2000 and 2002. Informed consent was obtained from all subjects. Resected tissues were fixed in $10 \%$ phosphate buffered formalin and paraffin embedded. One paraffin embedded block was selected at the centre portion of the gastric carcinoma in each case. Serial sections were cut to $4 \mu \mathrm{m}$ and used for histological examination and immunohistochemistry.

Carcinomas were classified as differentiated and undifferentiated types according to the criteria of the Japanese Gastric Cancer Association. ${ }^{3}$ Following the Laurén classification, ${ }^{1}$ well and moderately differentiated tubular adenocarcinomas and papillary adenocarcinomas were included in the differentiated type, and poorly differentiated tubular adenocarcinomas and signet ring cell carcinomas in the undifferentiated type. Depth of invasion was divided into T1 and T24 , according to the TNM classification. ${ }^{2}$

\section{Antibody production}

The cDNA fragment used encodes 124 amino acids of the $N$ terminus of PDXl but excludes the homeodomain (GenBank accession number; NM_000209), and was produced by polymerase chain reaction (PCR). The primer set was as follows: $\quad$ ''-AATTGGATCCATGAACGGCGAGGAGCAGT-3' (sense) and 5'-GCGCGAATTCTAAGACTTCATCCATGGGAA AGG-3' (antisense). The PCR product was digested with BamHI and EcoRI, and cloned into the pGEX-2TK vector (Amersham Biosciences, Piscataway, New Jersey, USA), which was then transfected into competent Escherichia coli cells. The sequence of the PDXI insert was confirmed by sequencing. Glutathione-S-transferase-PDXl fusion protein (GST-PDX1) was produced and purified with glutathione Sepharose 4B (Amersham Biosciences) according to the manufacturer's instructions. Rabbits were injected subcutaneously with $0.15 \mathrm{mg}$ of the fusion protein in Freund's complete adjuvant and boosted with $0.3 \mathrm{mg}$ of the same fusion protein in Freund's incomplete adjuvant five times every two weeks. Anti-PDXl antibody was treated with acetone powder derived from human liver ${ }^{24}$ to block nonspecific cross reactivity.

\section{Derivation of cells expressing PDX 1}

The PDXI cDNA sequence, including the full coding region, was obtained by PCR using CDNA from a gastric carcinoma cell line, KATOIII, with a primer set as follows: 5' AATTAAGCTTCGGGAGTGGGAACGCCACAC-3' (sense) and 5'-ATATGAATTCAGCAGCTCCTGCCTCTCATC-3' (antisense). The PDXI PCR product was subcloned into the mammalian expression vector pcDNA3.1 (Invitrogen, Groningen, Netherlands) (pcDNA3.1-PDX1). Plasmid DNA was purified with a HiSpeed Plasmid Midi Kit (Qiagen, Hilden, Germany) and verified by sequencing.

A human gastric carcinoma cell line, GT3TKB, was grown in Dulbecco's modified Eagle's medium containing 10\% fetal bovine serum (Sigma, St Louis, Missouri, USA) and $50 \mu \mathrm{g} / \mathrm{ml}$ kanamycin in a humidified atmosphere of $5 \% \mathrm{CO}_{2}$ at $37^{\circ} \mathrm{C}$, and transfected with pcDNA3.1-PDXl using TransIT (Mírus, Madison, New York, USA), as described by the supplier. The empty vector was also transfected in parallel as a negative control. After the transfected cells had been cultured for 48 hours and reached confluence, they were washed with phosphate buffered saline (PBS) and harvested with protein extraction buffer, as previously described. ${ }^{24}$

\section{Western blotting analysis}

Protein extracts $(25 \mu \mathrm{g})$ were separated by $12 \%$ sodium dodecyl sulphate-polyacrylamide gel electrophoresis and the separated proteins transferred to Immobilon-P membranes (Millipore, Bedford, Massachusetts, USA). After blocking for 14 hours at $4^{\circ} \mathrm{C}$ with $5 \%$ dehydrated skim milk (Difco, Detroit, Michigan, USA) in PBST (PBS with $0.05 \%$ Tween $20)$, the membranes were incubated with a 1:1000 dilution of anti-PDXI antibody for one hour at room temperature, then washed with PBST and incubated with Envision (Dako, Carpinteria, California, USA) diluted at 1:1000 with PBS for 30 minutes. We also used anti- $\alpha$-tubulin antibody (Santa Cruz Biotechnology, Inc, Santa Cruz, California, USA) for detection of an internal control. After washing, the blotted membranes were developed according to the chemiluminescence ECL protocol recommended by Amersham Biosciences. A predicted band was detected by the anti-PDXI antibody in

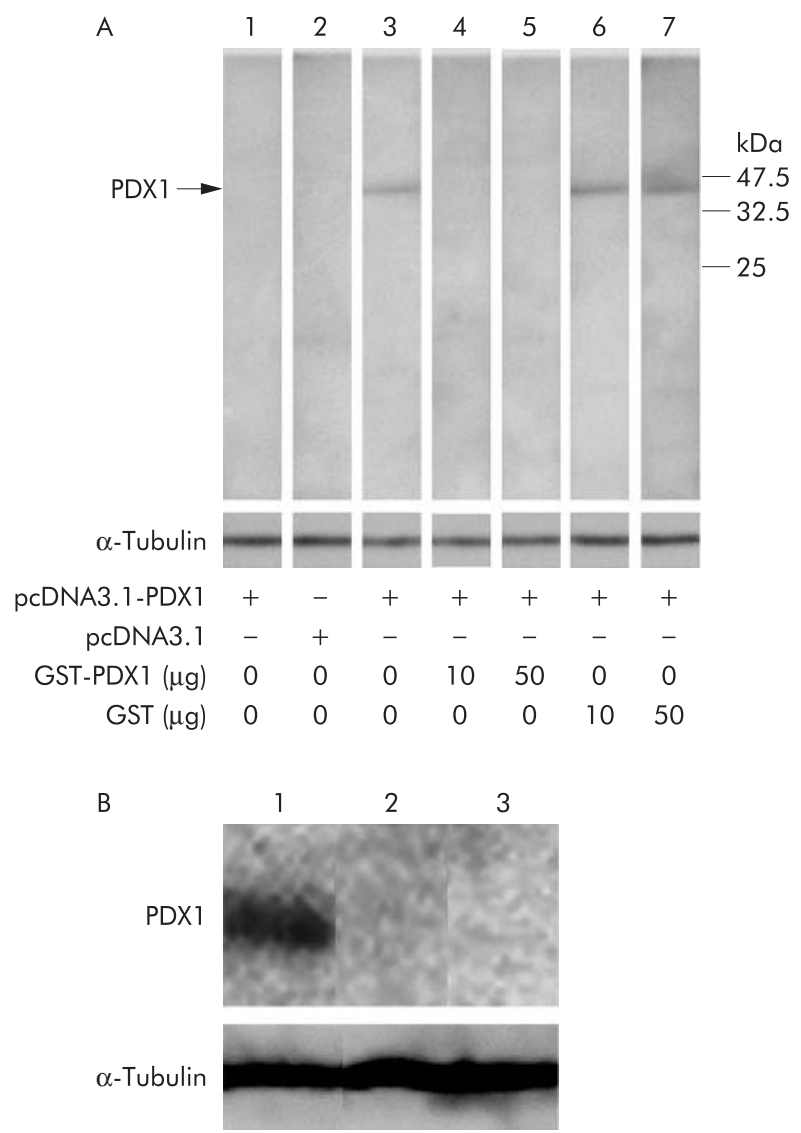

Figure 1 Confirmation of anti-pancreatic-duodenal homeobox 1 (PDX1) antibody by western blot analysis. (A) Lane 1: Band was not detected in GT3TKB transfected with pCDNA3. 1-PDX 1, reacted with preimmunised serum; lane 2: no band was seen in GT3TKB transfected with mammalian expression vector without PDXI CDNA, reacted with antiPDX1 antibody; lane 3: a predicted band was detected in GT3TKB transfected with PCDNA3.1-PDX1, reacted with anti-PDX1 antibody; lanes 4, 5: the band disappeared in GT3TKB transfected with pcDNA3.1-PDX1, reacted with anti-PDX1 antibody treated with 10 and $50 \mu \mathrm{g}$ of glutathione-S-transferase (GST)-PDX1, respectively; lanes 6, 7: the band did not fade out in GT3TKB transfected with pcDNA3.1-PDX1, reacted with anti-PDX1 antibody treated with 10 and $50 \mu \mathrm{g}$ of GST, respectively. $\alpha$-Tubulin was analysed as an internal control. (B) Lane 1: a band appears in extracted proteins from the normal antrum; lanes 2, 3: no band was observed in proteins from the normal corpus and colon, respectively. 

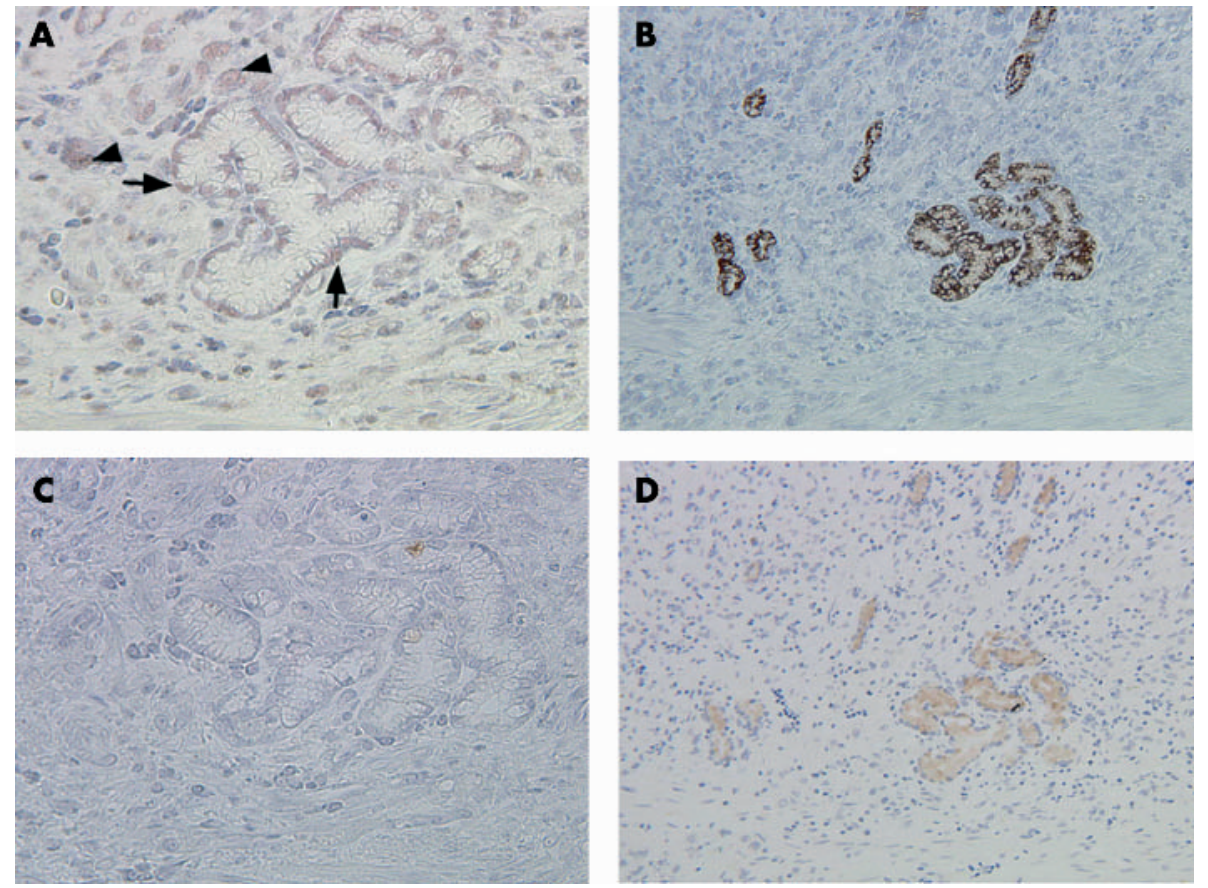

Figure 2 Expression of pancreatic-duodenal homeobox 1 (PDX1), pepsinogen I, and mucins MUC6 and MUC5AC in serial sections through pseudopyloric glands. (A) PDX1 is expressed in pseudopyloric glands surrounding carcinoma cells. Arrows indicate PDX1 expression in the nuclei of pseudopyloric gland cells. Arrowheads indicate PDX1 positive carcinoma cells. (B) MUC6 positive reactivity is also apparent. (C) No MUC5AC is expressed in the pseudopyloric glands. (D) The presence of pseudopyloric glands was confirmed by antihuman pepsinogen I monoclonal antibody staining. Original magnification: A, C, $400 \times ; B, D, 200 \times$.

$25 \mu \mathrm{g}$ of proteins extracted from GT3TKB cells transfected with pcDNA3.1-PDXI (fig 1A, lane 3) or from the normal antral epithelium (fig 1B, lane 1). But no band was detected in $25 \mu \mathrm{g}$ of proteins extracted from GT3TKB cells transfected with pcDNA3.1 (fig 1A, lane 2) and the normal corpus and colonic mucosae (fig 1B, lanes 2 and 3).

Furthermore, we confirmed the specific binding ability of the anti-PDXl antibody by blocking experiments with the peptide used in the production of the antibody or human GST (Sigma), as described previously. ${ }^{25}$ After incubation of $1 \mu \mathrm{l}$ of the anti-PDXl antibody with 10 or $50 \mu \mathrm{g}$ of GST-PDXl (fig 1A, lanes 4 and 5) or GST (fig 1A, lanes 6 and 7) for 14 hours at $4^{\circ} \mathrm{C}$, these mixtures were used in the blocking experiments. The band disappeared in samples treated with GST-PDXI but not with GST, indicating the specificity of the anti-PDXI antibody.

\section{Immunohistochemical analyses}

For immunohistochemistry, we employed the anti-PDXl polyclonal antibodies described above, and anti-mucin6 (MUC6) (CLH5; Novocastra Laboratories Ltd, Newcastle, UK), anti-MUC5AC (45Ml; Novocastra Laboratories Ltd), and antipepsinogen I monoclonal antibodies. ${ }^{26}{ }^{27}$ Sections were deparaffinised in xylene, rehydrated in ethanol, and then treated with $0.1 \%$ hydrogen peroxide in methanol for 30 minutes to inhibit endogenous peroxidase activity. Antigen retrieval for PDX1, MUC6, and MUC5AC was performed by microwaving the specimens in $10 \mathrm{mM}$ citrate buffer ( $\mathrm{pH}$ 6.0) for 15 minutes, followed by 20 minutes of incubation at room temperature. Antigen retrieval for pepsinogen I was accomplished by digestion with $0.2 \%$ trypsin solution in Tris-HCl buffer $(0.05 \mathrm{M}$; pH 7.6) containing $0.1 \% \mathrm{CaCl}_{2}$ at $37^{\circ} \mathrm{C}$ for 10 minutes. To block non-specific protein binding, we incubated the sections with $10 \%$ normal goat serum (Nichirei, Tokyo, Japan). Subsequently, sections were exposed overnight at $4^{\circ} \mathrm{C}$ to purified anti-PDXl, MUC6,
MUC5AC, or pepsinogen I antibodies, diluted at 1:1200, 1:500, 1:100, and $6 \mu \mathrm{g} / \mathrm{ml}$, respectively. After washing with PBS, binding was detected with the Envison+ kit (Dako) for PDXl, the Envision kit for MUC6 and MUC5AC, or the LSAB2 kit (Dako) for pepsinogen I, as recommended by the supplier. All specimens were counterstained with Mayer's haematoxylin. The specificity of anti-PDXl antibody binding in the immunohistochemical analysis was confirmed by blocking experiments with the peptide used in the production of the antibody or an irrelevant peptide, as described previously, ${ }^{25}$ and by identification using normal human gastric, duodenal, and pancreatic tissues. As observed previously in mice, ${ }^{1819}$ PDXI expression was specifically detected in the pyloric glands of the stomach, the crypts and Brunner's glands of the duodenum, and the islet cells of the pancreas, and was not found in the normal corpus mucosae of the stomach (data not shown).

For evaluation of immunohistochemistry, sections with more than $10 \%$ of cells demonstrating positive reactivity were scored as positive.

\section{Statistical analyses}

Data were generally analysed by the $\chi^{2}$ method. The relationship between PDXI expression and age was calculated using the Mann-Whitney U test. We further studied correlations of the immunohistochemical results with various clinicopathological factors using logistic regression analysis. The statistical software package applied was Statview 5.0 for Macintosh (SAS Institute, Inc., Cary, North Carolina). A p value of $<0.05$ was considered statistically significant.

\section{RESULTS}

Immunohistochemical analyses of PDX 1, MUC6, and MUC5AC expression in metaplasia

In order to detect pseudopyloric glands in the anatomical corpus, we analysed MUC6 and pepsinogen I expression. 

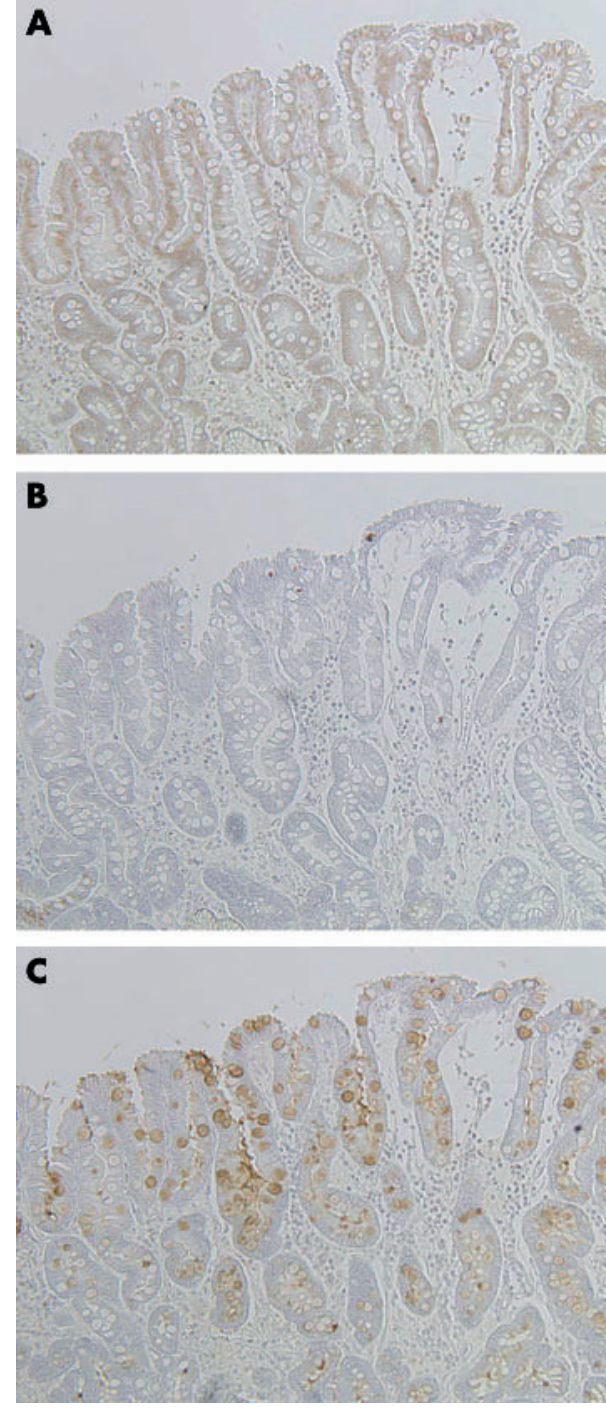

Figure 3 Expression patterns of pancreatic-duodenal homeobox 1 (PDX1) and the mucins MUC6 and MUC5AC in representative serial sections through intestinal metaplasia. (A) PDX1 positive reactivity is located in nuclei along the intestinalised epithelium. (B) No MUC6 expression is seen in intestinal metaplasia. (C) MUC5AC expression is evident in perinuclear portions of cells. Original magnification: $200 \times$.

Coexpression of the two markers is a defining feature of pseudopyloric glands while normal pyloric glands express only MUC6. ${ }^{828}$ MUC6 and pepsinogen I were evident in the perinuclear portions of pseudopyloric gland cells in the corpus in 46 of 95 primary gastric carcinoma cases (fig 2B, 2D). PDXI was expressed in the nuclei of cells lining the pseudopyloric glands in nearly all samples (45/46, 97.8\%) (fig 2A). Only seven cases (15.2\%) demonstrated MUC5AC expression in pseudopyloric glands.

In intestinal metaplasia, PDXI expression was found in the nuclei of goblet and columnar cells, and along the intestinalised epithelium (fig 3A). Expression of both MUC6 and MUC5AC (fig 3C) was detected in perinuclear areas of the cells. PDX1, MUC6, and MUC5AC positive reactivity was detected in $45(97.8 \%), 13(28.3 \%)$, and 41 (89.1\%) patients, respectively, of 46 cases with intestinal metaplasia.

\section{PDX 1 expression in gastric carcinomas}

We found PDXI expression in the nuclei of gastric carcinoma cells in $72(75.8 \%)$ of 95 gastric carcinomas (table 1, fig 4).
The frequency of PDXI positive reactivity was higher in differentiated type carcinomas $(39 / 43,90.7 \%)$ than in undifferentiated type $(33 / 52,63.5 \%)(\mathrm{p}=0.002)$. Tl carcinomas $(42 / 43,97.7 \%)$ expressed the PDXl protein more frequently than T2-4 carcinomas (30/52, 57.7\%) $(p<0.0001)$. Furthermore, the occurrence of PDXl positive reactivity in carcinomas without lymph node metastases (47/ $51,92.2 \%)$ was higher than in those with metastases $(25 / 44$, $56.8 \%)(\mathrm{p}<0.0001)$ (table 1$)$.

We further analysed correlation of PDXI expression with reference to three clinicopathological factors by logistic regression analysis. Histological type and depth of invasion were significantly and independently associated with PDXI expression in gastric carcinomas (histological type: odds ratio 0.233 (95\% confidence interval (CI) 0.064-0.856), $\mathrm{p}=0.03$; depth of invasion: odds ratio 0.055 (95\% CI 0.006-0.475), $\mathrm{p}=0.01$ ).

\section{Correlation of PDX 1 with MUC6 or MUC5AC expression in gastric carcinomas}

MUC6 and MUC5AC expression was detected in 46 (48.4\%) and $66(69.5 \%)$ of 95 cases, respectively. MUC6 was more frequently detected in PDX1 positive $(43 / 72,59.7 \%)$ than in PDXl negative $(3 / 23,13.0 \%)$ carcinomas $(\mathrm{p}<0.0001)$, as was MUC5AC (56/72 (77.8\%) PDX1 positive carcinomas $v$ 10/23 $(43.5 \%)$ PDXl negative; $p=0.002)$. The differentiated type $(28 / 43,65.1 \%)$, Tl carcinomas $(27 / 43,62.8 \%)$, and carcinomas without lymph node metastases $(30 / 51,58.8 \%$ ) expressed MUC6 protein more frequently than the undifferentiated type (18/52, 34.6\%), T2-4 carcinomas (19/52, 36.5\%), and metastasising carcinomas $(16 / 44,36.4 \%)$, respectively $(p=0.003, p=0.011, p=0.029)$. However, MUC5AC expression was not correlated with these pathological factors (data not shown).

To examine the characteristics of gastric carcinomas with pseudopyloric and pyloric gland phenotypes, we analysed the difference between double positive reactivity for PDXI and MUC6 (PDXl+/MUC6+) and the other reactivity types, including PDXl positive but MUC6 negative (PDXl+/ MUC6-), MUC6 positive but PDX1 negative (PDX1-/ MUC6+), and PDX1 and MUC6 double negative (PDXI-/ MUC6-), for each pathological criterion (table 2, fig 5). PDXI+/MUC6+ was more frequently observed in the differentiated type $(28 / 43,65.1 \%)$ than in the undifferentiated type $(15 / 52,28.8 \%)(p=0.0004)$. The frequency of PDX1+/MUC6+ was significantly higher in $\mathrm{Tl}$ carcinomas $(27 / 43,62.8 \%)$ than in T2-4 carcinomas $(16 / 52,30.7 \%)(p=0.0018)$. PDXI+/ MUC6+ was detected more often in carcinomas without metastases $(29 / 51,56.9 \%)$ than in carcinomas with metastases $(14 / 44,31.8 \%)(p=0.0145)$. By logistic regression analysis, histological type and depth of invasion were significantly and independently correlated with $\mathrm{PDXI}+$ / MUC6+ in gastric carcinomas (table 3 ).

Double positive expression of PDXI and MUC5AC (PDXI+/ MUC5AC+) was correlated with depth of invasion and lymph node metastases but not with histological type (table 2). PDXI+/MUC5AC+ exhibited significant and independent association only with depth of invasion by logistic regression analysis (table 3 , fig 5 ).

\section{PDX 1 and MUC6 expression in gastric carcinomas of the corpus and antrum}

To confirm the association of pseudopyloric glands with gastric carcinomas, we examined the correlation between PDXl expression or PDXI+/MUC6+ with sites of gastric carcinomas, such as the corpus, where PDXI is not normally expressed. Gastric carcinomas in the corpus and antrum appeared in 39 and 21 of 95 cases, respectively. Twenty five and seven carcinomas were located across the junction of the 


\begin{tabular}{|c|c|c|c|c|}
\hline \multirow[b]{2}{*}{ Clinicopathological factor } & \multirow[b]{2}{*}{ n } & \multicolumn{2}{|c|}{ PDX1 expression } & \multirow[b]{2}{*}{ p Value } \\
\hline & & Positive & Negative & \\
\hline $\begin{array}{l}\text { Age (y) } \\
\text { (mean (SD)) }\end{array}$ & $\begin{array}{l}95 \\
(63.4(10.7))\end{array}$ & $\begin{array}{l}72 \\
(63.3(10.8))\end{array}$ & $\begin{array}{l}23 \\
(63.5(10.5))\end{array}$ & $0.815^{*}$ \\
\hline \multicolumn{5}{|l|}{ Sex } \\
\hline Male & 69 & 50 & 19 & $0.218 \dagger$ \\
\hline Female & 26 & 22 & 4 & \\
\hline \multicolumn{5}{|l|}{ Histological type } \\
\hline Differentiated & 43 & 39 & 4 & $0.002 \dagger$ \\
\hline Undifferentiated & 52 & 33 & 19 & \\
\hline \multicolumn{5}{|l|}{ Depth of invasion } \\
\hline $\mathrm{T} 1$ & 43 & 42 & 1 & $<0.0001 \dagger$ \\
\hline T2-4 & 52 & 30 & 22 & \\
\hline \multicolumn{5}{|l|}{ Lymph node metastasis } \\
\hline Absence & 51 & 47 & 4 & $<0.0001 \dagger$ \\
\hline Presence & 44 & 25 & 19 & \\
\hline
\end{tabular}

corpus-antrum and cardia-corpus, respectively. Gastric carcinomas in the anatomical cardia were observed in three cases. PDXI was frequently expressed in carcinomas of the corpus $(30 / 39,76.9 \%)$ as well as antrum $(17 / 21,81.0 \%)$, which was not significantly different $(p=0.718)$. There was no significant difference in PDXI+/MUC6+ reactivity between the corpus (19/39, 48.7\%) and antrum (13/21, 61.9\%) $(p=0.329)$, suggesting that the pseudopyloric/pyloric gland phenotype may be related to carcinomas of not only the antrum but also the corpus.

\section{DISCUSSION}

To investigate the role of PDXI in gastric carcinogenesis, we examined its expression pattern in comparison with that of mucins MUC6 and MUC5AC in the human stomach by immunohistochemistry. PDXI positive cells were observed in pyloric glands in the antrum but not in the normal corpus mucosa, consistent with previous data for mice. ${ }^{19}$ We demonstrated PDXl expression in pseudopyloric glands of the human corpus for the first time and suggest that this transcription factor may be a regulatory protein that might contribute to their formation. G cells of the antrum are positive for PDXI, ${ }^{19}$ and forced PDXl overexpression causes immature enterocytes to differentiate into gastrin producing cells. ${ }^{29} \mathrm{G}$ cells are also present in pseudopyloric glands after healing of erosions in the human corpus. ${ }^{30}$ Furthermore, $P d x I$ deficient mice showed abnormal formation of the antrum. ${ }^{17}$ Taken together with the literature, our findings suggest that PDXI plays an important role in the development of pseudopyloric glands.

We further demonstrated that double expression of PDXI and MUC6 appeared in carcinomas of not only the antrum but also the corpus. Patterns of MUC6 expression were also consistent with those for PDXl in Brunner's glands of the duodenum and pyloric glands of the stomach. ${ }^{17} 1828$ These findings indicate that PDXI and MUC6 expression, similar to
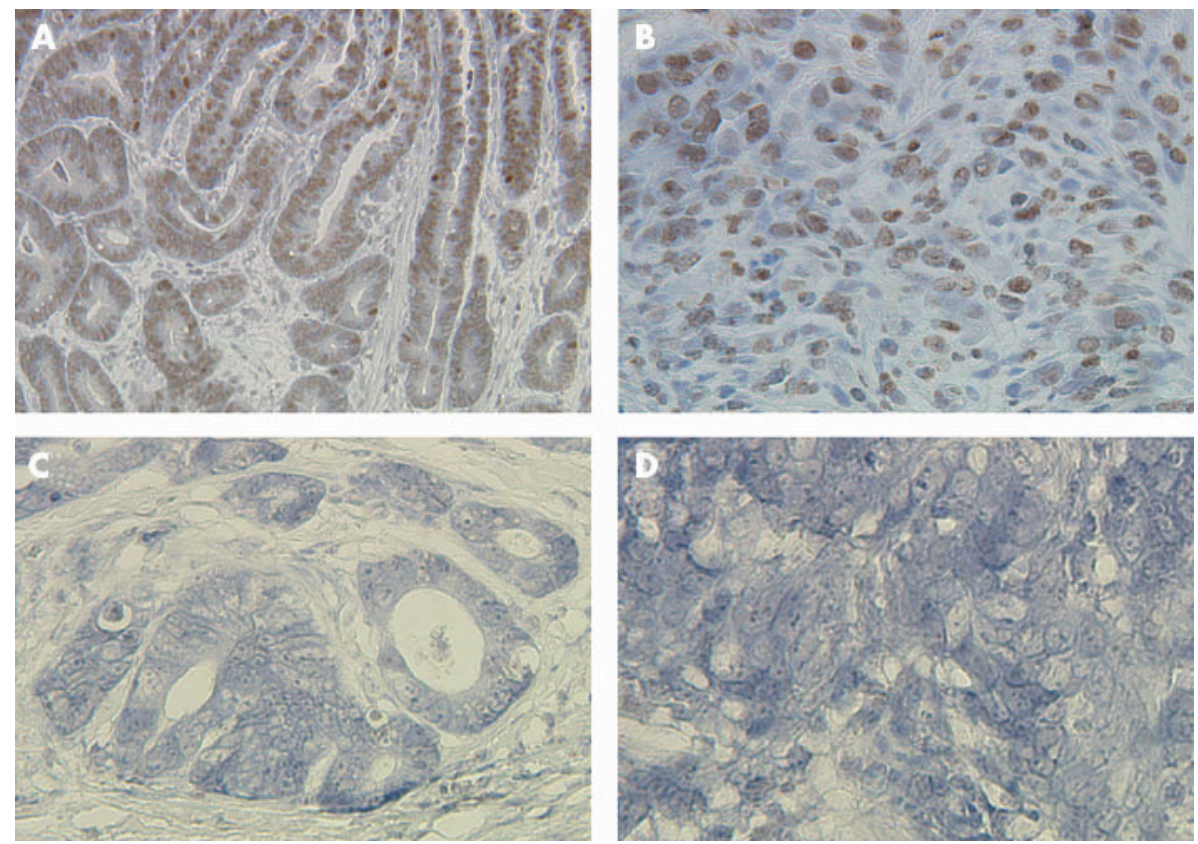

Figure 4 Pancreatic-duodenal homeobox 1 (PDX1) expression in gastric carcinomas by immunohistochemistry. (A, B) PDX1 positive reactivity is observed in differentiated and undifferentiated types of T1 carcinomas, respectively. (C, D) PDXI is negative in differentiated and undifferentiated types of T2-4 carcinomas. Original magnification: A, $200 \times ; B-D, 400 \times$. 


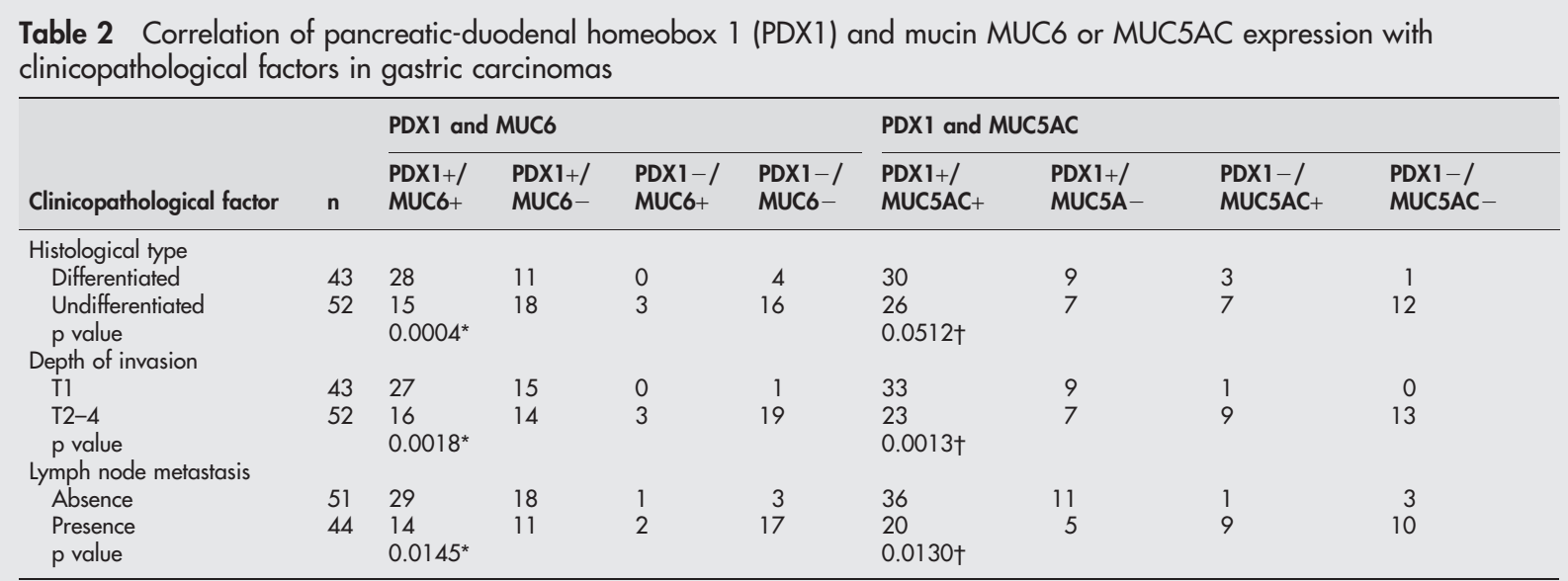

p value of PDX1 and MUC6* was analysed by the $\chi^{2}$ method comparing PDX1+/MUC6+ with the other reactivity types (PDXI+/MUC6-, PDX1-/MUC6+, and PDX1-/MUC6-). PDX1+/MUC5AC+ was compared with the others (PDX1+/MUC5AC-, PDX1-/MUC5AC+, and PDX1-/MUC5AC--)t.

pseudopyloric glands, is preserved in gastric carcinomas of the corpus. Rats undergoing Billroth II gastrectomy develop pseudopyloric glands and gastric neoplasms, ${ }^{31}$ and atrophic mucosa with gastric carcinomas was found as a continuous sheet of pseudopyloric glands, with or without foci of intestinal metaplasia, on mapping of resected stomachs. ${ }^{32}$ It is therefore conceivable that pseudopyloric glands, as well as intestinal metaplasia, may be associated with gastric carcinogenesis.

Intestinal metaplasia slowly spreads from the antrum to the corpus. $^{33}$ Differentiated type minute carcinomas are frequently observed in the antrum, ${ }^{56}$ and several authors have argued that intestinal metaplasia may develop subsequent to formation of pseudopyloric glands in the
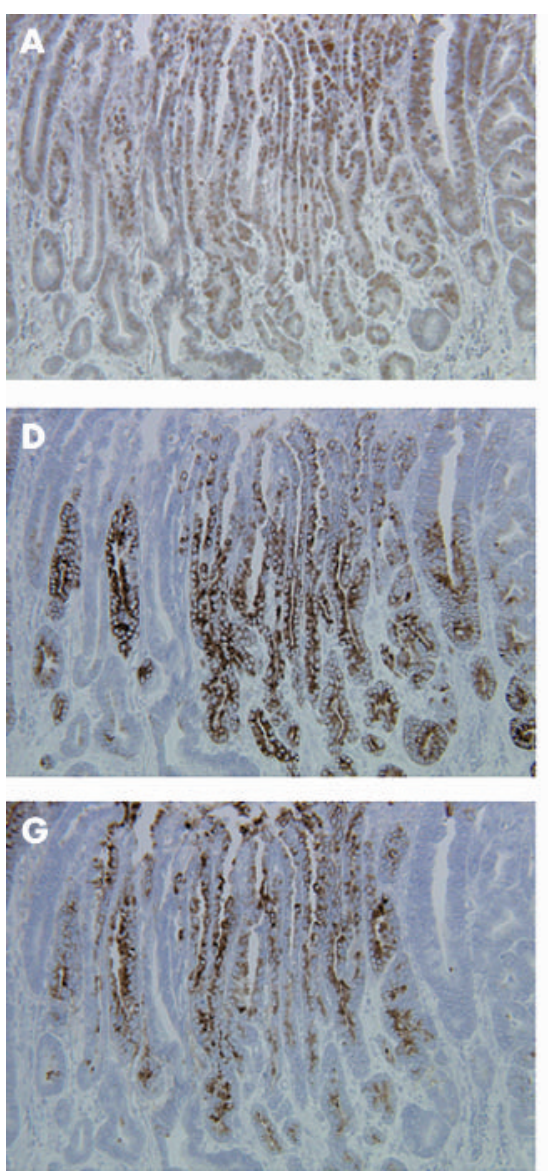
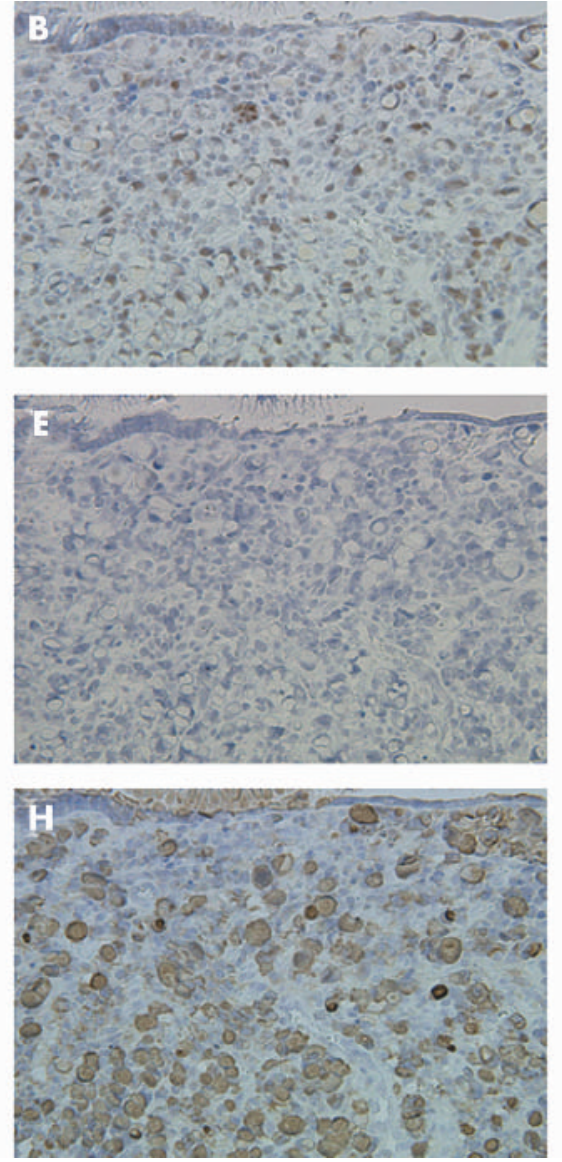
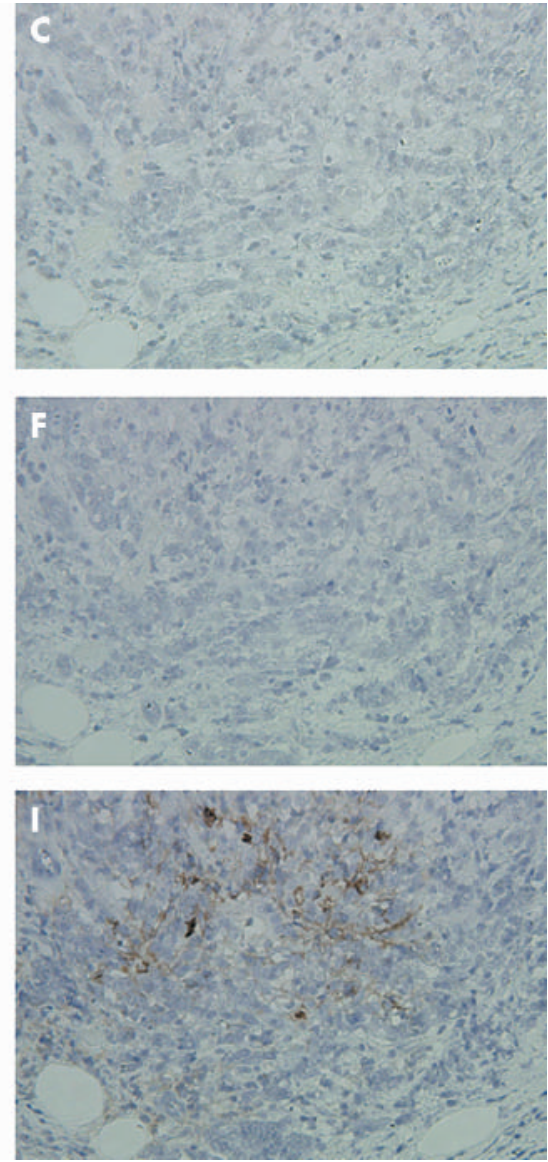

Figure 5 Comparison of pancreatic-duodenal homeobox 1 (PDX1) with mucin MUC6 and MUC5AC expression in serial sections through gastric carcinomas. (A, B) PDX1 expression is apparent in differentiated and undifferentiated type carcinomas, respectively. (C) PDX1 reactivity is not evident in undifferentiated type carcinoma. (D, G) MUC6 and MUC5AC expression is generally associated with PDX1 in differentiated type carcinoma. (E, F) MUC6 expression is not apparent in undifferentiated type carcinomas. $(\mathrm{H}, \mathrm{I})$ MUC5AC is expressed in undifferentiated type carcinomas. Original magnification: A, D, G, 200x; B, C, E, F, H, I, 400x. 
Table 3 Logistic regression analysis of pancreatic-duodenal homeobox 1 (PDX1) and mucin MUC6 or PDX1 and MUC5AC positive reactivity and clinicopathological factors in gastric carcinomas

\begin{tabular}{lllll}
\hline Positive reactivity & Clinicopathological factor & Odds ratio & $\mathbf{9 5 \%} \mathbf{C l}$ & p Value \\
\hline PDX1 and MUC6 & Histological type & 0.249 & $0.099-0.627$ & 0.003 \\
& Depth of invasion & 0.319 & $0.111-0.916$ & 0.034 \\
\multirow{2}{*}{ PDX1 and MUC5AC } & Lymph node metastasis & 0.886 & $0.302-2.601$ & 0.825 \\
& Depth of invasion & 0.307 & $0.109-0.861$ & 0.025 \\
& Lymph node metastasis & 0.631 & $0.232-1.716$ & 0.367 \\
\hline
\end{tabular}

corpus. ${ }^{10} 3435$ Our data indicate that differentiated type gastric carcinomas revealed expression of PDXl and MUC6 significantly higher than undifferentiated type. Thus intestinal metaplasia and differentiated type carcinomas may arise on the basis of pseudopyloric/pyloric glands.

We observed a significant association between PDXl expression and depth of invasion in gastric carinomas. Abate-Shen reviewed the two classes of homeobox genes ${ }^{11}$ and noted that positive tumour modulators, such as Hox, that are normally expressed in proliferating tissues and downregulated during differentiation, are often re-expressed in tumours. In contrast, negative tumour modulators, such as CDX2, that are expressed in differentiated tissues are often downregulated in tumours. For example, CDX2 was expressed in the normal epithelium of the colon and intestinal metaplasia of the stomach, and downregulated in colorectal and gastric carcinomas. ${ }^{12}{ }^{36}{ }^{37}$ In this study, another factor in the ParaHox gene family, PDXI, was expressed in differentiated tissues - that is, pseudopyloric/pyloric glands and intestinal metaplasia-with retention in early gastric carcinomas, but not in advanced lesions. Taken together with these findings, PDXI could also be classified as a negative tumour modulator in the stomach. However, it is possible that PDXI negative tumours tend to become advanced gastric carcinomas. Further studies are necessary to determine the role of PDX1 in gastric carcinogenesis.

In conclusion, we have presented evidence that PDXI is expressed in pseudopyloric glands of the corpus, intestinal metaplasia, and gastric carcinomas, and that gastric carcinomas of the corpus retain pseudopyloric gland phenotypic expression. Our results suggest that PDXI plays an important role in the development of pseudopyloric glands, and that this reflects a condition associated with gastric carcinogenesis.

\section{ACKNOWLEDGEMENTS}

This study was supported by a Grants-in-Aid for Scientific Research on Priority Areas from the Ministry of Education, Science, Sports, and Culture of Japan, and Research Fellowships of the Japan Society for the Promotion of Science for Young Scientists. We thank Drs H El-Zimaity and $\mathrm{H}$ Ota for advice regarding the experimental technique in this study, and Dr K H Kaestner for critical reading of the manuscript.

\section{Authors' affiliations}

H Sakai, X-L Li, Y Akiyama, S Miyake, Y Yuasa, Department of Molecular Oncology, Graduate School of Medicine and Dentistry, Tokyo Medical and Dental University, Tokyo, Japan

Y Eishi, M Koike, Department of Human Pathology, Graduate School of Medicine and Dentistry, Tokyo Medical and Dental University, Tokyo, Japan

T Takizawa, Department of Surgical Pathology, Graduate School of Medicine and Dentistry, Tokyo Medical and Dental University, Tokyo, Japan

N Konishi, Department of Pathology, Nara Medical University, Nara, Japan

M Tatematsu, Laboratory of Pathology, Aichi Cancer Centre Research Institute, Nagoya, Japan

\section{REFERENCES}

1 Laurén $\mathbf{P}$. The two histological main types of gastric carcinoma. Acta Pathol Microbiol Scand 1965;64:34-49.

2 Fenoglio-Preiser C, Muñoz N, Carneiro F, et al. Gastric carcinoma. In: Hamilton SR, Aaltonen LA, eds. World Health Organization classification of tumours. Pathology and genetics of tumours of the digestive system. Lyon: IARC Press, 2000:39-52.

3 Japanese Gastric Cancer Association. Japanese classification of gastric carcinoma. 2nd English edition. Gastric Cancer 1998;1:10-24.

4 Lewin KJ, Appelman HD. Carcinoma of the stomach. Atlas of tumor pathology, tumors of the esophagus and stomach, 3rd edn. Washington DC: Armed Forces Institute of Pathology, 1995:245-330.

5 Nakamura K, Sugano H, Takagi K. Carcinoma of the stomach in incipient phase: its histogenesis and histological appearances. Gann 1968;59:251-8

6 Mori M, Enjoji M, Sugimachi K. Histopathologic features of minute and small human gastric adenocarcinomas. Arch Pathol Lab Med 1989:1 13:926-31.

7 Correa P. A human model of gastric carcinogenesis. Cancer Res 1988;48:3554-60.

8 Dixon MF, Genta RM, Yardley JH, et al. Classification and grading of gastritis. The updated Sydney system. International Workshop on the Histopathology of Gastritis, Houston 1994. Am J Surg Pathol 1996;20:1161-81.

9 Helpap B, Hattori T, Gedigk P. Repair of gastric ulcer. A cell kinetic study. Virchows Arch A Pathol Anat Histol 1981;392:159-70.

10 Hattori T, Helpap B, Gedigk P. The morphology and cell kinetics of pseudopyloric glands. Virchows Arch B Cell Pathol Ind Mol Pathol 1982;39:31-40

11 Abate-Shen C. Deregulated homeobox gene expression in cancer: cause or consequence? Nat Rev Cancer 2002;2:777-85.

12 Bai YQ, Yamamoto H, Akiyama Y, et al. Ectopic expression of homeodomain protein CDX2 in intestinal metaplasia and carcinomas of the stomach. Cancer Lett 2002; 176:47-55

13 Brooke NM, Garcia-Fernandez J, Holland PW. The ParaHox gene cluster is an evolutionary sister of the Hox gene cluster. Nature 1998:392:920-2.

14 Silberg DG, Swain GP, Suh ER, et al. Cdx1 and Cdx2 expression during intestinal development. Gastroenterology 2000;1 19:961-71.

15 Silberg DG, Sullivan J, Kang E, et al. Cdx2 ectopic expression induces gastric intestinal metaplasia in transgenic mice. Gastroenterology 2002; 122:689-96.

16 Ohlsson H, Karlsson K, Edlund T. IPF1, a homeodomain-containing transactivator of the insulin gene. EMBO J 1993;12:4251-9.

17 Offield MF, Jetton TL, Labosky PA, et al. PDX-1 is required for pancreatic outgrowth and differentiation of the rostral duodenum. Development $1996 ; 122: 983-95$.

18 Stoffers DA, Heller RS, Miller CP, et al. Developmental expression of the homeodomain protein IDX-1 in mice transgenic for an IDX-1 promoter/lacZ transcriptional reporter. Endocrinology 1999;140:5374-81.

19 Larsson LI, Madsen OD, Serup P, et al. Pancreatic-duodenal homeobox 1 role in gastric endocrine patterning. Mech Dev 1996;60:175-84.

20 Jonsson J, Carlsson L, Edlund T, et al. Insulin-promoter-factor 1 is required for pancreas development in mice. Nature 1994;371:606-9.

21 Yuasa Y. Control of gut differentiation and intestinal-type gastric carcinogenesis. Nat Rev Cancer 2003;3:592-600.

22 Schlempter RJ, Riddell RH, Kato Y, et al. The Vienna classification of gastrointestinal epithelial neoplasia. Gut 2000:47:251-5.

23 Dixon MF. Gastrointestinal epithelial neoplasia: Vienna revisited. Gut 2002; $51: 130-1$

24 Harlow E, Lane D. Using antibodies - a laboratory manual, 2nd edn. New York: Cold Spring Harbor, 1999.

25 Silberg DG, Furth EE, Taylor JK, et al. CDX1 protein expression in normal, metaplastic, and neoplastic human alimentary tract epithelium. Gastroenterology 1997; 113:478-86

26 Tatematsu M, Ichinose M, Miki K, et al. Gastric and intestinal phenotypic expression of human stomach cancers as revealed by pepsinogen immunohistochemistry and mucin histochemistry. Acta Pathol Jpn 1990;40:494-504.

27 Konishi N, Matsumoto K, Hiasa Y, et al. Tissue and serum pepsinogen I and II in gastric cancer identified using immunohistochemistry and rapid ELISA. J Clin Pathol 1995:48:364-7.

28 Bartman AE, Buisine MP, Aubert JP, et al. The MUC6 secretory mucin gene is expressed in a wide variety of epithelial tissues. J Pathol 1998;186:398-405.

29 Yamada S, Kojima H, Fujimiya M, et al. Differentiation of immature enterocytes into enteroendocrine cells by Pdxl overexpression. Am J Physiol Gastrointest Liver Physiol 2001;281:G229-36. 
30 Fujimoto S, Kimoto K, Inokuchi H, et al. G-cell population and serum gastrin response to cimetidine-OXO test meal in relation to histopathological alterations in resected stomachs from patients with peptic ulcer disease. Gastroenterol Jpn 1980;15:101-7.

31 Miwa K, Kamata T, Miyazaki I, et al. Kinetic changes and experimental carcinogenesis after Billroth I and II gastrectomy. Br J Surg 1993;80:893-6.

32 El-Zimaity HM, Ota H, Graham DY, et al. Patterns of gastric atrophy in intestinal type gastric carcinoma. Cancer 2002;94:1428-36.

33 Sugano H, Nakamura K, Kato Y. Pathological studies of human gastric cancer. Acta Pathol Jpn 1982;32:329-47.

34 Tsutsumi $Y$, Nagura H, Watanabe K, et al. A novel subtyping of intestinal metaplasia of the stomach, with special reference to the histochemical characterizations of endocrine cells. Virchows Arch A Pathol Anat Histopathol 1983;401:73-88

35 Inada K, Nakanishi H, Fujimitsu Y, et al. Gastric and intestinal mixed and solely intestinal types of intestinal metaplasia in the human stomach. Pathol Int 1997:47:831-41.

36 Ee HC, Erler T, Bhathal PS, et al. Cdx-2 homeodomain protein expression in human and rat colorectal adenoma and carcinoma. Am J Pathol 1995; 147:586-92.

37 Mallo GV, Rechreche H, Frigerio JM, et al. Molecular cloning, sequencing and expression of the mRNA encoding human CDX1 and CDX2 homeobox. Down-regulation of $\mathrm{Cdx} 1$ and $\mathrm{Cd} \times 2$ mRNA expression during colorectal carcinogenesis. Int J Cancer 1997;74:35-44.

\section{GI SNAPSHOT}

\section{Menetrier disease}

\section{Question}

A 31 year old man presented with nausea, epigastric discomfort, and weakness. He reported coffee ground emesis, melena, and had a history of iron deficiency anaemia of two years requiring oral iron supplementation and repeated blood transfusions. He had no other significant medical, surgical, or family history. Computed tomography scan of the abdomen revealed marked diffuse thickening of the gastric walls without any lymphadenopathy. Upper gastrointestinal endoscopy revealed giant folds with a polypoid appearance in the body and fundus of the stomach (fig 1). Mucosal biopsies of the fundus, body, and antrum were obtained. Stains for Helicobacter pylori were negative. The history and histological findings of this case are consistent with what disease?

See page 338 for answer

\section{A Cardenas, C Kelly} Beth Israel Deaconess Medical Center, Harvard Medical School, Boston, Massachusetts 02215, USA

Correspondence to: Dr A Cardenas, Beth Israel Deaconess Medical Center, Harvard Medical School, 110 Francis St-Suite 8E, Boston, Massachusetts 02215, USA; acardena@bidmc.harvard.edu
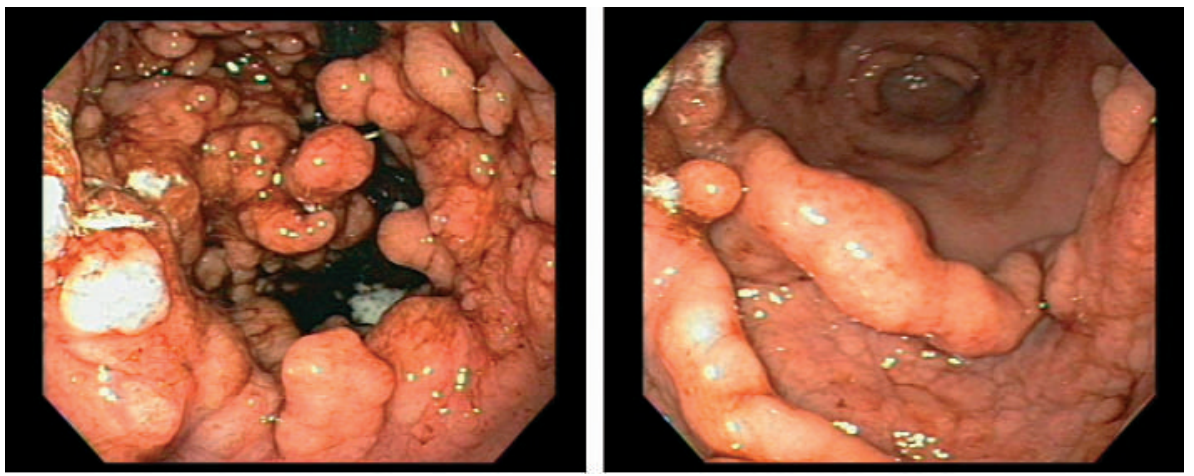

Figure 1 Upper gastrointestinal endoscopy of the stomach revealing giant folds with a polypoid appearance in the body and fundus. 